\title{
EL FILÓSOFO DEL ALDEA (1625) DE BALTASAR MATEO VELÁZQUEZ: RECEPCIÓN TEXTUAL E HIPÓTESIS AUTORIAL ${ }^{1}$
}

\author{
DAVID GonZÁLEZ RAMÍREZ \\ Universidad de Málaga \\ davidgr@uma.es
}

\section{Mateo Velázquez (o Baltasar del Angulo) y Liñán y Verdugo: ¿LA Doble máscara DE FRAY AlONSO REMÓN?}

medio camino entre un manual de cortesanía, un diálogo didáctico y una
colección de novelas enmarcadas, El filósofo del aldea (1625) de Baltasar
Mateo Velázquez ha merecido hasta hoy una atención crítica bastante pobre y aquellos que se han acercado al texto han sido atraídos por sus problemas de autoría ${ }^{2}$. Fue Bourland (1927: 47) la primera que relacionó temáticamente El filósofo y la Guía y avisos de forasteros (1620) de Antonio Liñán y Verdugo, situándolas bajo el signo del didactismo; por esas mismas calendas varios investigadores estaban buscando en archivos noticias para tratar de averiguar la identidad de Liñán y Verdugo, nombre que muy tempranamente sería relacionado con el de Velázquez. Zarco Cuevas (1929) publicó un trabajo en el que, a partir de diferentes deducciones, sostenía que el verdadero autor de la Guía fue el mercedario fray Alonso Remón, nacido en Vara de Rey (Cuenca), que había confesado en

1 Este trabajo se inscribe en el marco de dos proyectos en los que participo: «Italian Novellieri and Their Influence in Renaissance and Baroque European Culture: Editions, Translations, Adaptations» (ORTO113ACX), dirigido por Guillermo Carrascón (Università degli Studi di Torino), y «Recepción y Canon de la Literatura Española en el siglo XX» (MICINN. Plan Nacional I+D+i. FFI2013-43451-P), coordinado por José Lara Garrido (Universidad de Málaga).

2 Modernamente esta obra fue rescatada por Emilio Cotarelo y Mori (1906) en su «Colección selecta de antiguas novelas españolas», junto con las de Miguel Moreno (este texto ha sido digitalizado por la University of Toronto Libraries en la siguiente dirección: https://archive. org/details/coleccinselect04castuoft. Existe también una edición digital de El filósofo en la plataforma Scribd (sin datos de edición ni de su responsable): http://es.scribd.com/doc/91390972/ VELAZQUEZ-BALTASAR-MATEO-El-filosofo-de-la-aldea. 
sus Entretenimientos y juegos honestos (1623: h. 4v) poner «en público doce diferencias de libros en mi nombre y seis en el ajeno». Van Praag (1935) se encargó de arrojar nueva luz sobre los estudios del autor de la Guía cuando entrevió ciertas sospechas (nombres, lugares...) entre el texto de Liñán y El filósofo; fue cuando lanzó la hipótesis de que bajo la máscara de ambos nombres (Liñán y Velázquez) podía ocultarse un mismo escritor.

Van Praag fue el primero en advertir una serie de concomitancias que hacían levantar suspicacias sobre las autorías de ambas obras y a partir de él cuantos se han ocupado de este asunto han redondeado los resultados de su trabajo. Observó Van Praag, por ejemplo, que — según rezaba en la portada — la procedencia del supuesto autor de El filósofo era la «villa de Varaderrey», exactamente el mismo lugar donde decía haber nacido el personaje que lleva las riendas del diálogo en la Guía, el Maestro. Igualmente, Ana Agudo y Vallejo, desconocida poetisa, publicó un poema laudatorio en los preliminares de cada una de las dos obras - y en el de El filósofo reconoce a Angulo como su «tío» ([1625] 1906: 154)— , mientras que el padre Alonso Remón es citado en ambos textos de forma muy entusiasta ${ }^{3}$. Además de estas analogías, Van Praag advirtió concordancias estructurales entre ambos libros, en los que también detectó semejanzas en sus mecanismos narrativos, temas e ideas afines, y otras correspondencias estilísticas y léxicas. Basándose en las palabras prologales de El filósofo — «quiso mi suerte que me hallase con estos papeles, casi en borrón [...], y determinado a ponerlos en público, luego les di, por dueño y señor, a quien ya por fama e inclinación lo es de su autor», ([1625] 1906: 159)—, Van Praag, con excesiva prudencia, planteó la posibilidad de que, si no se trataba de un seudónimo, Velázquez pudo recibir «el manuscrito de otro» para acabar publicándolo a su nombre.

Uno de los principales estudiosos de la obra de Alonso Remón, Manuel Fernández Nieto (1973), aportó más noticias para fortalecer los vínculos entre El filósofo, la Guía y el fraile de la Merced. La atenta lectura de la obra completa de Alonso Remón le hizo descubrir que en uno de sus libros, La vida del Caballero de Gracia (1620), se aboceta el plan de la Guía y avisos de forasteros con una precisión absoluta (1973: 130). En esta obra se narra que a su personaje principal

[...] le nació el deseo de escribir algo y ponerlo en publicación [...]. Pero entre otros papeles se halló uno que intitulava Guía importante para los forasteros que vienen a esta Corte, a negociar, pretender, para que no se distrayan, ni anden ociosos, ni caigan en los peligros en que suelen caer, los que se dexan llevar de los vicios y libertades de esta vida de Corte.

\footnotetext{
Incluso en una referencia de El filósofo se remite a una obra de Alonso Remón, las Advertencias católicas y políticas, «que aún se están de mano, porque no las ha puesto en público el que las hizo» ([1625] 1906: 225), lo que añade una sospecha más en las relaciones entre el autor de esta obra y el fraile mercedario.
} 
Fernández Nieto también documentó, a partir de los libros de matrícula de la Universidad de Alcalá, los estudios conjuntos que realizaron Maximiliano de Céspedes (el autor del discurso apologético que aparece al frente de la Guía, en el que se reconoce a Liñán y Verdugo como viejo amigo) y Alonso Remón. Además de estas pruebas textuales y documentales, en relación a El filósofo del aldea Fernández Nieto añadió un dato sustancial; Remón, en su Casa de la razón y el desengaño (1625: h. 4v), recordaba que una idea que estaba desarrollando ya apareció en otro libro suyo y también la recogió su «sobrino don Baltasar de Angulo en El filósofo de la [sic] aldea, que dedicó a v. m.». Finalmente, sobre la Guía y El filósofo volvió Ángel-Raimundo Fernández (1983), extractando pasajes con temas comunes y comparándolos con otros de los Entretenimientos y juegos honestos de Alonso Remón. Fernández estableció algunos puntos de conexión entre estas tres obras desde un enfoque estilístico e ideológico muy sugerentes.

En resumidas cuentas, los rastreos sobre la identidad de Baltasar Mateo Velázquez (o Baltasar de Angulo, nombre con el que lo cita Alonso Remón y que aparece en los sonetos laudatorios, además de ser el reproducido por Nicolás Antonio en su corpus bibliográfico, [1696] (1996), I: 181) han resultado frustrantes, pues lo único que se ha podido recuperar hasta ahora — con la inseguridad que originan las homonimias y la carencia de otros datos contrastables - son dos aprobaciones firmadas por un tal Baltasar de Velázquez en torno a los años veinte: Diego Suárez, Cartilla y arte menor de contar, 1619, y Salcedo Coronel, Ariadna, 1624 (Fernández Nieto, 2013: 64). En todo caso, que tal persona fuese sobrino de Alonso Remón, bien pudo ser real, aunque la obra no hubiese sido escrita por él mismo 5 . Pero la ausencia de otros libros firmados por Velázquez/Angulo limita el campo de investigación al haz de coincidencias textuales y referencias nominales que se detectan en el esquema triangular que forma junto a Liñán y Verdugo (que de igual manera solo cuenta en su currículum literario con la Guía y avisos de forasteros) y Alonso Remón (en cuyas obras se avistan puntos de intersección con la Guía y El filósofo que hacen presumir una relación más allá de lo puramente casual o imitativo). A propósito de estas dos obras, es lógico que, mientras no se localice un documento irrefragable que garantice la paternidad de Alonso Remón, todas las investigaciones se quedarán en los márgenes de las conjetura; pero este

4 Este trabajo de Fernández Nieto fue recogido en su libro sobre el fraile mercedario (1974). Recientemente (2013) ha vuelto sobre el mismo asunto en un artículo que aborda el género en el que se enmarcan ambas obras, aunque acaba repitiendo los mismos argumentos sobre la posible autoría compartida que ya presentó hace cuarenta años, sin aportar novedad alguna.

5 No sería el primer caso de una obra aparecida bajo el nombre de un familiar; en 1592 Juan Díaz Rengifo firmó el volumen Arte poética española, redactada por su hermano Diego García Rengifo, y en 1663 Cristóbal Lozano publicó sus Soledades de la vida a nombre de su sobrino Gaspar Lozano. 
hecho no impide que de forma paralela a la documentación de archivo podamos secundar una hipótesis fundada en el auxilio del análisis contrastivo de los textos.

\section{TRANSMisión TEXTUAL DE EL FILÓSOFO DEL ALDEA}

a) Primera edición

EL FILOSOFO | DEL | ALDEA, | Y sus conuersaciones familiares y exem-|plares, por casos, y sucessos casuales. | Por el Alferez don Baltasar Mateo Velaz | quez, natural de la villa de | Varaderrey. | A Don Iuan de Valdes y Melendez. | [Decoración heráldica] | CON PRIVILEGIO. | En Madrid, Por Diego Flamenco, y à su costa. Año 1625.

En $8^{\circ}$, 8 h+ 96 f. Sign.: $\uparrow^{8}$, A-M ${ }^{8}$.

Ejemplares: BNF: Z.32358. Österreichischer Bibliothekenverbund: AC103965337 .

b) Segunda edición

EL FILOSOFO | DEL | ALDEA, | Y SVS CONVERSACIONES | familiares, y exemplares, por ca-|sos, y sucessos | casuales. | POR EL ALFEREZ DON | Baltasar Mateo Velazquez, | natural de la villa de Varaderrey. | A DON IVAN DE VALDES | y Melendez. | CON LICENCIA | En Pamplona, por Pedro Dullort, | año de Mil y seyscientos y | veynte y seys.

En $8^{\circ}, 8 \mathrm{~h}+88$ f. Sign.: $\Upsilon^{8}$, A-P ${ }^{8}$.

Ejemplares: RAE: 3-IX-85*. BNE: R/5557 y R/13316. RAH: 1/2809. British Library: C.62.a.14. University of Florida: 170V434f. University of Calgary Library.

6 Anoto todos los ejemplares de los que he llegado a tener noticias a través de catálogos impresos y en línea. Para describir el testimonio conservado en la H.S.A. (un cuarto estado de edición de la tercera edición de la obra) me he basado en la descripción de Bourland (1927: 191), pues me ha sido imposible acceder a una copia del original. En la Biblioteca Pública Lambert Mata (Ripoll, Girona) hay un ejemplar de la tercera edición (R.192), pero al carecer de los preliminares se hace casi imposible determinar a qué estado de edición pertenece (se puede consultar su digitalización a través de la siguiente dirección: http://www.bibgirona.cat/pandora/viewer. vm?id=0000001444\&page=1\&lang=ca [Fecha de consulta: 8 de septiembre de 2014]. Por otra parte, en mis rastreos por catálogos en línea ha aparecido un nuevo estado de edición en un catálogo de la Staatsbibliothek zu Berlin-Preussischer Kulturbesitz (XI 3658), cuya descripción del título responde a Sucesos prodigiosos en diferentes casos casuales y prodigiosos, publicado a costa de Juan Fernández en Zaragoza. Hecha la consulta, desde la biblioteca me indican que el ejemplar se perdió durante la Segunda Guerra mundial, por lo que esta información de catálogo (si no responde a una amalgama de datos incorrectos: el título, el librero y la ciudad son los mismos que ya aparecen en otros estados de edición) hay que ponerla en cuarentena mientras no tengamos la posibilidad de contrastarla. La posibilidad de un cotejo de todos los ejemplares conservados de la tercera edición nos ayudaría a clasificar cada uno de sus estados y probablemente nos depararía alguna sorpresa entre sus preliminares.

7 Existe una reproducción digital que puede consultarse a través de la siguiente dirección: http:// books.google.es/books?id=JdFcAAAAcAAJ\&pg=PA52\&dq=Fil\%C3\%B3sofo+del+aldea\&hl=

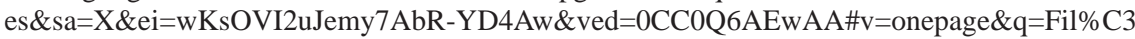
\%B3sofo\%20del\%20aldea\&f=false [Fecha de consulta: 8 de septiembre de 2014]. 
c) Tercera edición. Primer estado de edición

EL FILOSOFO | DEL ALDEA. | Y SVS CONVERSACIONES FAMI- | liares, y exemplares, por casos, y sucessos | casuales, y prodigiosos. | SV AVTOR. | EL ALFEREZ DON BALTASAR MATEO | Velazquez. | DEDICADO. | A DON PEDRO GVTIERREZ DE | Miranda, Assentista de Millones de su | Magestad, que Dios guarde. | CON LICENCIA, EN ZARAGOZA | Por Diego de Ormer, Impressor de la Ciudad y Hos- | pital Real de nuestra Señora de | Gracia.

En $8^{\circ}$, 4h + 106 f. Sign.: $q^{4}$, A-N ${ }^{8}, \mathrm{O}^{7}$.

Ejemplares: BNE: R/16266, R/15005 (2), 2-18233 y 2-5664.

d) Tercera edición. Segundo estado de edición

EL FILOSOFO | DEL ALDEA. | Y SVS CONVERSACIONES FAMI-|liares, y exemplares, por casos, y sucessos | casuales, y prodigiosos. | SV AUTOR. | EL ALFEREZ DON BALTASAR MATEO | Velazquez. | DEDICADO. | A DON PEDRO GVTIERREZ DE | Miranda, Assentista de Millones de su | Magestad, que Dios guarde. | CON LICENCIA, EN MADRID | Acosta de Iuan Fernandez Librero, viue arri-|mado al Estudio de la Compañia | de Iesvs.

En $8^{\circ}, 4 \mathrm{~h}+106$ f. Sign.: $\Upsilon^{4}$, A-N $^{8}, \mathrm{O}^{7}$.

Ejemplares: BNE: R/19527.

e) Tercera edición. Tercer estado de edición

EL FILOSOFO | DEL ALDEA. | Y SVS CONVERSACIONES FAMI-|liares, y exemplares, por casos, y sucessos | casuales, y prodigiosos. | SV AVTOR. | EL ALFEREZ DON BALTASAR MATEO. | Velazquez. | DEDICADO. | A D. DIEGO DE ARROYO Y | Rozas, Escriuano mayor de Rentas | de su Magestad. | Con licencia. En Zaragoça, Por Diego de Hor-|mer, Impressor del Hospital de nuestra | Señora de Gracia.

En $8^{\circ}, 2 \mathrm{~h}+106$ f. Sign.: [ ] $]^{2}, \mathrm{~A}-\mathrm{N}^{8}, \mathrm{O}^{7}$.

Ejemplares: H.S.A. Universität Hamburg: A/71909. Universitat de Barcelona: 07XVII-2331. Biblioteca de Andalucía (Granada): R.233319

$8 \quad$ Este ejemplar, que carece de todos los preliminares, perteneció a Cayetano Alberto de La Barrera. Contiene una nota inicial entre las hojas modernas que anteceden al cuerpo del volumen, cuya caligrafía indiscutiblemente pertenece a La Barrera, en la que se puede leer lo siguiente: «El Filósofo del Aldea, y sus Conversaciones familiares. Su Autor el Alferez Don Balthasar Mateo Velazquez. Zaragoza: por Diego Dormer. s. a. (=ázia 1650; según Salbá)». En este volumen también se imprimió una hoja impresa con la «TABLA DE LOS SVCESSOS DESTE LIBRO» que no aparece en los demás consultados y que se corresponde con el contenido del libro: «Como se deuen Criar los Hijos. Sucesso de Polino, y Sigeldo. Sucesso de las dos Isabeles. Sucesso de Agueda la mal Casada. Sucesso del Rey Euandro. Sucesso de Paulo el Estudiante. Sucesso de Polino. Sucesso de vn Despensero. Sucesso de Bindro. Sucesso de los Alcaldes. Sucesso de dos amantes».

9 Este ejemplar se puede consultar en línea a través de la Biblioteca Virtual de Andalucía: http://

Edad de Oro, XXXIII (2014), pp. 193-210, ISSN: 0212-0429 
f) Tercera edición. Cuarto estado de edición

SVCESSOS PRODIGIOSOS | EN DIFERENTES CASOS CASVALES, | y prodigiosos. | CONTADOS | POR EL FILOSOPHO DE ALDEA. | SV AVTOR. | EL ALFEREZ DON BALTASAR MALO | Velazquez. | Decoración. | Por Diego de Ormer, Impressor de la Ciudad, | y Hospital Real de Nuestra Señora | de Gracia.

En $8^{\circ}, 4 \mathrm{~h}+106$ f. Sign.: $\Upsilon^{4}, \mathrm{~A}-\mathrm{N}^{8}, \mathrm{O}^{7}$.

Ejemplares: H.S.A.

Durante los años en el que el Consejo de Castilla aceptó la propuesta de la Junta de Reformación para que no se concediesen licencias para editar libros de comedias y novelas (1625-1634), El filósofo del aldea se imprimió en dos ciudades diferentes: Madrid y Pamplona. En realidad, esta decisión administrativa no llegó a afectarle, pues los documentos legales que avalaban su divulgación editorial fueron firmados y otorgados en 1624, y el texto de 1626 se imprimió fuera del término jurisdiccional de Castilla. Pero ante todo, la obra presentaba una traza de manual educativo, por lo que los relatos incluidos podían entenderse más bien como ejemplos morales de cada una de las lecciones que tenían lugar en cada conversación. Fue el impresor Diego Flamenco el primero que costeó el texto, que se imprimió, según reza su colofón, en 1624; si bien el trabajo de edición terminaría en fechas muy próximas al año siguiente, o bien ya entrados en él, pues en la portada, para que el libro no quedase anticuado, apareció el año 1625.

Tras la reedición pamplonesa, la obra no volvió a ver la letra de molde hasta mediados de siglo. El éxito de este género literario y la capacidad de los autores para mantener actualizado el mercado editorial prácticamente evitaron que se tuviesen que reeditar libros de esta naturaleza. Lo que resulta verdaderamente peregrino es la fascinante trama editorial — derivada de unos evidentes intereses comerciales - que presenta la impresión de Zaragoza, de la que derivan numerosos estados de edición diferentes, en los que el cuerpo del texto fue respetado y tan solo fueron modificados sus preliminares $\left(\right.$ título $^{10}$, dedicatario, ciudad...). La fecha exacta de esta edición difícilmente la podremos conocer, pero hay una serie de indicios (como por ejemplo el periodo de impresión de Diego Dormer o la adición de una novela facticia que apareció en La quinta de Laura de Castillo Solórzano, publicada en 1649) que colocan la obra en los primeros años de la década de los cincuenta.

www.bibliotecavirtualdeandalucia.es/catalogo/catalogo_imagenes/grupo.cmd?path=1011772\& posicion=1\&presentacion=pagina [Fecha de consulta: 8 de septiembre de 2014].

10 El título con el que apareció uno de estos estados, Sucesos prodigiosos, es una reelaboración del que Pérez de Montalbán le dio a uno de sus libros, Sucesos y prodigios de amor (Madrid, 1624). 
El componedor de la edición zaragozana cometió múltiples desbarres con el original, introduciendo numerosas erratas en la foliación y otras alteraciones en la transcripción que descubren la incuria con la que se trabajó en la imprenta regentada por Diego Dormer ${ }^{11}$. Al final de la obra, y seguramente por capricho del propio editor, se incluyó la novela El duende de Zaragoza de Castillo Solórzano, recogida en La quinta de Laura y narrada por Florisia en el sarao del sábado (1649: 198-219), poniendo fin al retiro milanés en el que habían pasado algunos días Laura, ciertos familiares y su correspondiente servicio, a la espera de que los duques de Milán y Ferrara firmasen la paz. Pero el encargado de incorporar esta adición espuria en la tertulia de El filósofo, aunque se cuidó de redactar una escueta continuación en el marco actancial para conectar el final de la obra con el agregado, no eliminó el cierre del libro de Mateo Velázquez ([1625] 1906: 310-311):

Con esto puso fin el filósofo del aldea a la conversación de aquel día, y todos rieron la burla hecha a Floro, diciendo que había tenido su merecido, por haber usado de vocablos semejantes en auditorio tan incapaz de entenderlos; con que el aldeano se despidió de don Juan y de los demás, ofreciéndoles que pasadas las pascuas, que ya estaban cercanas, volvería a continuar las conversaciones pasadas con diferentes materias y cosas agradables y ejemplares, y ellos se lo pidieron así.

En la versión zaragozana de El filósofo del aldea justo a continuación se lee lo que copio ([1625] 1906: 313): «Dijo don Juan: "Pues antes que nos de[s]pidamos contaré yo otro caso bien gustoso y pasaremos un rato de gusto"; a lo cual se detuvo el aldeano, y dijo: "Pues este rato no es de perder”. Y con esto comenzó don Juan». La novela de Castillo Solórzano a su vez también era la que cerraba su colección, y el editor de esta reedición añadida y aumentada no se cuidó de eliminar la parte del marco de La quinta de Laura, asumiendo por tanto una incongruencia notoria por aludir a una narradora y a un título que ninguna relación guardaban con la obra de Velázquez. Con este cierre apareció la obra en su versión definitiva ([1625] 1906: 335):

Gustosos dejó a todos la novela de la hermosa Florisia; diéronle las gracias de haberles entretenido también. Rematose la tarde con sonoras letras que cantaron y aquí el autor deste libro da fin a él, pidiendo perdón de sus yerros y ofreciendo segunda parte de La quinta de Laura, que saldrá con sus bodas y fiestas hechas a ellas presto.

Las motivaciones que tuvo Dormer por rescatar editorialmente El filósofo del aldea quizá haya que ligarlas a su interés por sacar al mercado — tras una década

11 Destaca, entre las más flagrantes, la repetición en la foliación; llegado al folio 96 el cajista debió de interpretar mal el numeral (entendiendo el 6 como un 0) y continuó con el 92. Por tanto, la edición contiene cinco folios más de los 106 numerados. 
de discontinuidad en la que la novela corta parecía haber encallado- una obra que podía estar temáticamente cerca de otras que en Zaragoza se acababan de imprimir. Solo unos años antes, los libreros Alfay y Navarro trataron de reactivar el mercado con la preparación de la primera antología de novelas cortas de varios autores, divulgada con el título de Novelas amorosas de los mejores ingenios de España, en la que se recogieron cuatro piezas de Lope y otras cuatro de Castillo, nombre que sin embargo fue silenciado (González Ramírez 2007). Solo un año más tarde vieron la luz también en la misma ciudad dos colecciones póstumas de Castillo Solórzano: Sala de recreación y La quinta de Laura. En particular, sobre La quinta de Laura es notorio el estado inacabado en el que llegó a manos del editor (sin preliminares y casi con toda seguridad carente de algunos de los títulos de sus novelas $\left.{ }^{12}\right)$.

Si apenas podemos sospechar la razón por la que Dormer reeditó El filósofo del aldea, aún menos podemos deducir qué le llevó a estampar esta novela de Castillo al final de la obra. Hubiese sido plausible (y estaría en consonancia con la urgente preparación del texto en la imprenta) que el editor hubiese tratado de adelantar una pieza inédita de Castillo, pero esta hipótesis se derrumba en tanto que la fuente inequívoca de la que se valió el impresor fue la edición de La quinta de Laura, y no ninguna versión manuscrita. Además el editor lo hubiese resaltado en la portada como efecto comercial y nos daría la respuesta de sus motivaciones. Lo que podemos asegurar es que la inclusión de El duende de Zaragoza marca el término post quem que nos permite situar esta obra a partir de la fecha aceptada por consenso por la crítica: $1650^{13}$.

12 Al estudiar esta colección de Castillo, Cotarelo (1906 y en Moreno y Velázquez, 1906) mostró sus sospechas sobre la paternidad de algunas novelas del conjunto (en particular de El duende de Zaragoza, que interpretó como «obra vagabunda»), la elección de los títulos (el general y el de las novelas) y la ultimación del texto (que había llegado sin prólogo ni dedicatoria), si bien, mientras avanzaba en su estudio prologal, y contradictoriamente, acabó por admitir que «todas las novelas» pertenecían a Castillo Solórzano, aunque no tenía toda la seguridad de que el resultado último de la edición hubiese sido autorizado: «Todas estas circunstancias, bien se comprende, dificultan la admisión como auténtico del tomo, aunque aisladamente pertenezcan a Castillo todas las novelas que contiene» (1906: LXXVII). Algunos años más tarde, Alan Soons (1978: 138) secundó las sospechas de Cotarelo y concluyó que «it is probable that neither frame-story nor novellas are by Castillo in their entirety». Parece palmario (y en este punto hay que aceptar las reticencias de Cotarelo) que Castillo no dejó la colección dispuesta para la imprenta, por lo que resulta difícil negar la intervención de terceros en la obra. En cualquier caso, su estructura compositiva y el parentesco estilístico son razones suficientes para garantizar la autoría de Castillo al frente de la obra (González Ramírez 2012).

13 Para Ripoll (1991: 66) estas ediciones de El filósofo eran «posteriores al menos a 1649». Cautamente, Velasco de la Peña (1998) no registró esta edición en su catálogo, que alcanza hasta la mitad del siglo xvII. En él vemos que hasta esa fecha Diego Dormer menor tuvo una intensa actividad editorial, imprimiendo hasta una veintena de publicaciones. En la monografía de Velasco de la Peña (1998: 106 y 117) se dan noticias sobre la utilización de Dormer de la 
LiÑÁn, VeLÁzqueZ y REMÓN: ÉTICA Y ESTÉTICA EN TRES OBRAS COETÁNEAS

Además de la serie de nombres propios que se cruzan en los textos de la Guía, los Entretenimientos y El filósofo (la villa de Vara de Rey, el Maestro Remón, Ana Agudo y Vallejo — presunta sobrina de Baltasar del Angulo- y Baltasar del Angulo — que se reconoce como sospechoso sobrino de Remón-), muchos han sido los que han sacado a relucir la abundancia de refranes y proverbios que se encuentran en estas obras, así como las concomitancias de giros idiomáticos o expresiones que ofrecen una evidencia más de la posible autoría compartida. Hay quienes consideran que las coincidencias en niveles lingüísticos de diferente orden es una prueba del ADN de un escritor; es incuestionable que la lengua y el estilo de un autor marcan los criterios de su modus scribendi, y en muchos casos los estudios de frecuencia léxica han puesto de manifiesto datos estadísticos sugerentes para probar (más allá de desechables imitaciones) la paternidad de una obra. Sin embargo, ni la coincidencia de un vocabulario, ni la utilización de idénticas estructuras gramaticales, ni tampoco la fijación por ciertos asuntos que impliquen una filiación ideológica, serían una prueba discriminatoria si estos rasgos en la escritura no se diesen de forma constante y se advirtiese una interiorización del discurso y una recurrencia léxica o fraseológica casi repetitiva.

Se han puesto en concordancia algunos temas o ideas que aparecen tanto en la Guía de Liñán como en El filósofo de Velázquez y en los Entretenimientos de Remón; las opiniones sobre el lenguaje culto y oscuro, o los pareceres sobre las comedias y su licitud han ocupado varias páginas de estos estudios. Sin embargo, penetrando algo más en la concepción ideológica de estas obras descubrimos que hay una fuerte ligazón entre las tres que se superpone a los argumentos repetidos o incluso a la coincidencia de rasgos lingüísticos. Hay en cada uno de estos libros (más evidente en los Entretenimientos y quizá de modo disfrazado en los otros dos, que aparecieron como colecciones de novelas) un sustrato doctrinal que construye intencionadamente un discurso ético, desde una concepción cristiana y unos principios reformistas, con el que se trata de instruir a la república para que huya de la ociosidad, madre de todos los vicios. Me permitiré en los siguientes párrafos pergeñar algunos aspectos de esta prédica catequística, a sabiendas de que el asunto merece un tratamiento de mayor hondura.

Siguiendo la cronología editorial de estas obras, la Guía y avisos de forasteros se presenta, bajo el signo horaciano del delectare et prodesse, como una

Imprenta del Hospital de Nuestra Señora de Gracia, en donde editó una obra en 1645. El filósofo del aldea sería probablemente la segunda obra que Dormer publicó en el taller tipográfico del Hospital de Nuestra Señora de Gracia. 
conjunción de avisos (diálogos) y escarmientos (novelas) para que el recién llegado a la Corte, mientras está resolviendo pleitos o solicitando prebendas, no se preste a los entretenimientos vanos, acierte en aquellos trámites que debe realizar (encontrar posada, buscar un buen agente para los negocios, etc.) y emplee su tiempo honestamente (huyendo de los ociosos, visitando iglesias, etc.). Detrás de este organigrama, esta obra encierra un programa reformador en el que se protege la religiosidad, se hace una apología de la monarquía y una reivindicación patriótica, y se advierte de los perjuicios de la ociosidad: «Porque después de la obligación primera y principal que los ha de mover y llevar [a los forasteros], que es la defensa de la religión cristiana, el servicio de su rey y príncipe, y la reputación de la nación y patria, ésta es la segunda: el procurar trabajar para descansar» ([1620] 2011: 212).

En la Guía se localizan numerosas llamadas de atención sobre el peligro que encarna la plaga de ociosos y vagabundos por las calles de la ciudad y la vida indecente que muchos llevan, por lo que la intención que muestra el Maestro en sus avisos es la de que el forastero huya «[...] ya de ruines amigos, [...], ya de mujeres fáciles, engañosas y deshonestas, [...], ya de juegos y distraimientos, de donde se siguen mayores daños y desgracias [...] a que están sujetos los mortales hombres mientras peregrinan en el profundo piélago del inconstante mar desta vida miserable» ([1620] 2011: 167) ${ }^{14}$. Estas palabras de don Antonio (aludiendo a la «guía cristiana» que el Maestro les había ofrecido hacer) quintaesencian el sentido de la obra: evitar la corrupción de la sociedad tratando de impedir que aquellos que viajan hasta la Corte (cada vez más por la centralización administrativa) caigan en sus trampas y engaños. En el aviso cuarto, el Maestro recordaba cómo «en las repúblicas grandes» «siempre ha habido hombres sobrados y ociosos, de cuya ociosidad resultan notables daños», por lo que «siempre se ha procurado instituir leyes y publicar sanciones y premáticas para remediar los daños que acarrean y traen consigo [...] este género de gente ociosa y vagamunda». Liñán entendía que el momento de crispación social que vivía era crucial para que «jueces y gobernadores» pusieran todos sus desvelos en conocer «cómo se vive y en qué se entretiene esta gente sobrada» ([1620] 2011: 225).

14 Precisamente sobre el tema de los juegos se extiende el autor en el aviso quinto, en el que aconsejaba que el forastero «huya de los entretenimientos vanos y ocupe el tiempo en sus negocios». Se insiste en que son demasiados los que conceden su tiempo «de balde» «al juego, a la chacota, a la mormuración y a otros vanos entretenimientos, y aun viciosos y culpables, que es lo peor; de que se dará estrechísima cuenta al partir desta vida»; a su vez, uno de los dialogantes se interesa por conocer la opinión del Maestro respecto a que el forastero, toda vez que haya resuelto sus negocios, pueda ocupar «las horas y ratos que le sobraren» en «oír una comedia», «en pasearse por la calle Mayor o el Prado», en «ir a una casa de conversación y jugar dos reales», «a los trucos», «a los cientos», «a la pelota», «a los bolos» 0 «a la argolla» ([1620] 2011: 241-243). 
Celebraba el autor de la Guía que el aumento de la población y la llegada masiva a la Corte hubiese supuesto un control más agudo, «aumentando nuevas salas de gobierno y pulicía, dividiendo el cuidado de rondas y velas por cuarteles», pero se lamentaba de que «apenas» parecían «razonables y suficientes los medios imaginados y los remedios prevenidos» para frenar la llegada de forasteros y averiguar en qué lugares se hospedaban y qué modo de vida tenían ([1620] 2011: 175). Con su obra Liñán trató de crear un ideal de república que evitase dar cobijo a cuantos huían de sus ocupaciones y se entregaban a la ociosidad y al vicio. Desde la vertiente literaria, el mensaje cifrado de Liñán representa en buena medida una continuación de los discursos que arbitristas como Pedro de Valencia, Argensola o Pérez de Herrera redactaron para erradicar la plaga de ociosos y vagabundos que inundaban la Corte (González Ramírez 2010). Además, muchos de los parlamentos de los dialogantes de la Guía son un eco manifiesto de las advertencias que Jerónimo Castillo de Bobadilla selló en su Política para corregidores (1597) o Pedro de Guzmán dejó impresas unos años antes en sus Bienes del honesto trabajo y daños de la ociosidad (1614).

$\mathrm{Si}$, en definitiva, la obra de Liñán hay que entenderla también como un memorial de normas y avisos para mantener el estado libre de holgazanes, que son quienes acercan el daño y el vicio a la sociedad, los Entretenimientos y juegos honestos y recreaciones cristianas, para que en todo género de estados se recreen los sentidos sin que se estrague el alma (simbólico y representativo título) de Alonso Remón representan un intento por asegurar que todos los estratos sociales mantengan su identidad y no se corrompan entregándose a pasatiempos indecorosos. La finalidad de esta obra es proponer «algunas ocupaciones y ejercicios» para «el alma y el espíritu» «que pidan menos atención y menor cuidado» que su habitual «trabajo espiritual» (1623: f. 1v). Si la Guía es una obra de «aviso y advertencia», los Entretenimientos contienen «muchas advertencias importantes para el bien común de una república cristiana» (1623: h. 4v).

Desde las teorías aristotélicas sobre la necesidad de compensar el tiempo de dedicación al trabajo con los ratos de recreación (idea que en la literatura española tuvo una gran resonancia en el prólogo de las Novelas ejemplares de Cervantes), otros escritores latinos como Cicerón o teólogos como Santo Tomás escribieron sobre los equilibrios que el alma y el cuerpo deben alcanzar para evitar estragos y mantener la serenidad y la recreación del espíritu. Todo encaminado a conseguir la eutrapelia, esa virtud que según explicaba Remón era la

[...] que en los juegos y entretenimientos guarda decoro a las personas, modestia al ejercicio y pone razón en el fin a que se dirige de que sea bueno, ora sea con palabras entretenidas, ora refiriendo cuentos o casos sucedidos, ora diciendo donaires ejemplares, más virtuosos que ridículos, ora haciendo juegos, o jugando a cosas 
que vayan dirigidos a recreación y no a ganancia. Que alegren y no ofusquen, que entretengan y no distraigan, que enseñen ejemplos y no inciten a vicios (1623: f. 2).

Complemento y continuación a su modo del Fiel desengaño contra la ociosidad y los juegos. Utilísimo a los confesores y penitentes, justicias y los demás a cuyo cargo está limpiar de vagabundos, tahúres y fulleros la República cristiana (1603) de Luque Fajardo, los Entretenimientos de Remón se presentan como un manual para «diferenciar con facilidad lo virtuoso de lo vicioso y que pueda ser pecado, y lo lícito de lo no lícito» (1623: f. 4). En su guía cristiana, Remón aceptaba que todos los estados sociales gozasen de unas posibilidades para entretenerse, y les ofrecía una serie de mandamientos encaminados a ocupar el tiempo de ocio, pero insistía en que todo ha de mirarse con «desvelo» y con «ánimo», pues «es fácil perderse y por recrearse engañarse», y de aquí surgen los daños para la república y la ofensa de Dios y del prójimo. En definitiva, su obra enseñaba «[1]as reglas del arte cristiano de cuál es entretenimiento loable y honesta recreación y cuál no» (1623: f. 4v). En sus Entretenimientos y juegos honestos Remón hizo un repaso por todos los órdenes de la sociedad (desde los soldados hasta las mujeres o los príncipes y religiosos) para ofrecerles a cada uno de ellos unas orientaciones sobre los entretenimientos, recreaciones y juegos que les son permitidos, tratando que el tiempo de ocio del que disponen lo destinen siempre a actividades honestas. También este libro, por tanto, es una aguja de marear, con instrucciones para el bien común de la república.

Hasta ahora no se ha visto en El filósofo del aldea más que una obra que presenta una fisonomía semejante a la de la Guía, entreverando "conversaciones» con cuentos y novelas. Tales diálogos tenían un fin declarado: adoctrinar sobre varios temas de interés social como el de la crianza de los hijos, el tomar estado, la gobernación, la fortuna y el lenguaje. Pero en la carta que el alférez Baltasar Mateo Velázquez le dirige al lector en los preliminares de la obra, reconoce el motivo (que bien puede funcionar como estrategia discursiva) que le llevó a componer su libro: reprimir la ociosidad, contra la que lanza una dura invectiva:

La ociosidad para todos los corazones humanos es veneno, y para los que profesan la milicia, veneno y pestilencia, porque cuanto son los deste género de gente más inquietos y levantados de pensamientos, ya de ambición, ya de venganza, tanto más fomentado de la ociosidad [...]. De aquí ha nacido el procurar ocupar el ingenio cuando huelgan las manos. Del de mi caudal corto es este parto aborto, más por huir el ocio que por publicar mi ignorancia ([1625] 1906: 161).

En este sentido, resulta más que sintomático el anuncio inicial con el que se abre la obra; el marco de las novelas aparece representado por una tertulia a la que invitan a un labrador recién llegado a la aldea del que todos alaban sus 
conocimientos. No añadiría nada nuevo a la típica cornice de un conjunto de novelas cortas si no se indicase un matiz que no puede pasar inadvertido:

Juntábanse en su casa de este caballero personas nobles y de letras muy de ordinario, y tratábase de materias diversas, aunque tenía lastimado a don Juan (que este era su nombre) el ver que estos buenos ratos tuviesen tan mal fin, como para siempre en jugar, quitándose las haciendas, y resultando de ahí otros mayores inconvenientes en ofensa de Dios y del prójimo, que razón fuera que parara ya este parar en república tan concertada como la nuestra ([1625] 1906: 166).

La causa de invitar al filósofo a esta tertulia no es otra sino la de aprovechar los ratos de ocio y conversación, que se están desperdiciando en juegos poco edificantes en los que se aventura la hacienda. Para evitar que esta relajación y entrega al juego vaya a peor, el dueño de la casa piensa que el filósofo podría orientar las conversaciones hacia asuntos provechosos. Hay una vinculación evidente entre esta obra y la Guía y avisos de forasteros, con la que comparte, además de la morfología, un fin común, como es el de sacarle partido a las sobremesas con un propósito beneficioso para la república; como diálogos catequísticos sui generis, en ambos casos un Maestro y un filósofo (ejes de los diálogos y de las conversaciones) son los responsables de dar las instrucciones para que se huya de la ociosidad (amiga del vicio y del pecado), mientras que el resto de dialogantes ofrece una serie de ejemplos (en forma de novelas o casos) para advertir de los peligros de seguir lo contrario. Las narraciones breves que integran ambas colecciones tienen todas un final desdichado; el propósito reformador es evidente desde el momento en que el resto de los oyentes (y lectores) deben sacar el ejemplo a partir del escarmiento que reciben los personajes que desobedecen aquello que se dicta en los avisos. La conexión con los Entretenimientos resulta también patente desde el momento en el que se advierte la intención de don Juan por darle un giro a las tertulias vespertinas y evitar los estragos del juego. En este sentido, tanto la Guía como El filósofo se ajustan desde su planificación inicial al programa reformador que organiza Remón en torno a sus Entretenimientos.

\section{La CASA de La Razón y el desenGaño (1625) de Alonso Remón Como posible Clave DEL ENIGMA}

Si es indiscutible que existe una filiación ideológica entre las tres obras analizadas, hay una cuarta en la que Fernández Nieto (1973: 434-435) reparó para ponerla en relación con la Guía y El filósofo por razones de diferente valor. El especialista en la obra de Remón avistó un par de motivos en la Casa de la razón y el desengaño (Madrid, 1625) que le llamaron poderosamente la atención. El primero es que el dedicatario es exactamente el mismo que el de El filósofo, hecho 
que — como he recordado al inicio de este trabajo— es puesto de relieve incluso por Alonso Remón, que reconocía como sobrino a su autor, mudándole el nombre con respecto al de la portada de la obra: don Baltasar del Angulo. El segundo aspecto en el que paró mientes Fernández Nieto guarda relación con la indiscutible correlación que existe entre el inicio de la Casa de la razón y el desengaño y el de la Guía, donde se nos ofrece la presentación del lugar y de los personajes:

Salían de Palacio un maestro graduado en Artes y Teología y un cortesano antiguo llamado don Antonio, dado también a las letras humanas; el uno pleiteante y el otro pretendiente. Encontraron a un caballero mozo, con quien en Granada, en ocasión de otros pleitos y pretensiones, habían tenido familiar conversación y amistad, así por haber acertado a vivir en un mismo barrio, como por decir sus negocios orden a un mismo tribunal y jueces (Guía y avisos de forasteros, [1620] 2011: 165).

Salía una tarde de invierno, a gozar del sol y del campo, por la carrera que va de Madrid a Nuestra Señora de Atocha, una persona eclesiástica, maestro en Teología, y por no llevar ni la vista ni el ánimo ociosos, íbase entreteniendo en la lección de un libro, cuya profundidad debía de ser tan considerable y pedir atención tanta, que aunque dos amigos suyos, el uno llamado Fructuoso y el otro Prudencio, que habían salido en su seguimiento, le llamaron a voces, no les respondió (Casa de la razón y el desengaño, 1625: f. 1).

Pero estos detalles carecerían de mayor trascendencia si no los relacionamos con otros que aparecen desde las primeras páginas de esta obra, en las que Remón parece ofrecer una serie de indicios y evidencias que de forma alusiva y elusiva solicitan la autoría de la Guía y de El filósofo. En el prólogo al lector no pasa inadvertido el ensayo que bosquejó el mercedario, a propósito de la extensión de los libros, sobre la originalidad y el plagio, sosteniendo que el autor que formaba un «volumen grande» acababa cargando con «más hurtos ajenos». Alonso Remón reconocía que había "puesto a vista y en el Tribunal de los Censores ordinarios» toda una suerte de «diferencias de libros» (cuyos títulos recopiló), «sin otros muchos papeles sueltos a diversos propósitos». Remató estas palabras prologales con la reivindicación de la variedad de su obra, que abrazaba «materias tan diferentes como son las de espíritu, las de historia, las políticas y de razón de estado, las predicables, las morales, las teólogas y aún algunas de las letras humanas» (1625: h. 2v).

Si avanzamos desde el paratexto al discurso literario, la Casa de la razón y el desengaño, según se nos advierte en las primeras páginas, es una obra destinada principalmente a mostrar caridad, «amparo y protección»a «los pobres huérfanos y peregrinos» (1625: f. 2). El Maestro que guía el diálogo alega un ringlero de autoridades que subrayan la ayuda a los «peregrinos y forasteros». Con este volumen, Alonso Remón trató de ayudar a esas «almas» que llegaban «donde tanta 
necesidad hay [...] en un golfo de vicios y un mar sin suelo de desórdenes y confusión» (1625: ff. 7v-8). A través de «diferentes cuadros y lienzos» (1625: f. 11v) el Maestro les enseñará un hospital a modo de «edificio imaginario» donde se deben mirar los «ciegos, los engañados y los locos» (1625: ff. 13v-14) ${ }^{15}$. Nos encontramos ante un diálogo indirecto que, mutatis mutandis, comparte con la Guía $y$ avisos de forasteros su interés por ayudar al recién llegado a la Corte para que evite sus trampas.

No considero que sea fortuito que el libro en el que Alonso Remón pondera el volumen de su obra (resaltando al final aquellas de «letras humanas») y lanza un mensaje abogando por la originalidad, su inicio coincida imprevistamente con el de otro que acababa de salir de otro taller de imprenta madrileño ${ }^{16}$. Como tampoco me parece ocasional que en las palabras preliminares de esta obra saque a colación un título como el de El filósofo del aldea. Sigilosamente Alonso Remón pudo en este libro suyo tender una tupida red de interconexiones con la Guía (imitando sutilmente su inicio y su conformación dialogal) y reclamar la atención sobre un volumen de «letras humanas» como El filósofo, que también habría podido componer por esas fechas.

Estamos en una línea temporal muy reducida que discurre desde 1620 con la aparición de la Guía y presumiblemente la ultimación de la Casa de la razón, que continúa con los Entretenimientos en 1621 (aunque se publican un par de años más tarde) y que termina en 1624 con la concesión de licencias de El filósofo, cuyo pie de imprenta es del año siguiente. Alonso Remón, en las obras que firmó, concibió un proyecto ideológico, enraizado en unos principios cristianos, del que bien pudo hacer partícipes algunos de esos libros «de letras humanas» que publicó con nombre «ajeno». El estudio comparativo de las tres obras analizadas evidencia una serie de analogías que permiten sostener, con las prevenciones imprescindibles en este tipo de trabajos, una hipótesis que fue apuntada hace casi un siglo y que Fernández Nieto completó con sugerentes datos: en el último periodo de su trayectoria literaria, Alonso Remón se encargó de componer dos obras como la Guía y El filósofo, situadas en la órbita de las propuestas reformistas que en obras de otro tenor estaba defendiendo.

Recibido: 30/08/2014

Aceptado: 15/10/2014

\footnotetext{
15 En esta alegoría que es la Casa de la razón y el desengaño, las concomitancias puntuales que presenta con la Guía, en cuanto a estilo y motivos, son muchas, referidas a los resortes dialogales, al modo de educar los hijos, a las observaciones sobre las mujeres cortesanas, sobre los mohatreros, sobre los entretenimientos vanos...

16 No se puede obviar que la Casa de la razón y el desengaño, aunque terminó imprimiéndose en 1625 , contiene datadas sus aprobaciones y la suma del privilegio en 1620, exactamente el mismo año en el que apareció la Guía.
} 


\section{OBRAS CITADAS}

Antonio, Nicolás [1696] (1996). Bibliotheca hispana nova, I-II. Madrid: Visor.

Castillo Solórzano, Alonso de (1649). Sala de recreación. Zaragoza: Pedro Lanaja y Lamarca, a costa de José Alfay.

- (1649). La quinta de Laura. Zaragoza: Hospital Real y General de Nuestra Señora de Gracia, a costa de Matías de Lizau.

Cotarelo y Mori, Emilio (1906). «Introducción» a Alonso de Castillo Solórzano, La niña de los embustes. Madrid: Librería de la Viuda de Rico, pp. v-Xc.

FERnÁndez NiETo, Manuel (1973), «Nuevos datos sobre autores de novela cortesana». Revista de Archivos, Bibliotecas y Museos, 76, pp. 423-437.

(1974). Investigaciones sobre Alonso Remón, dramaturgo desconocido del siglo XVII. Madrid: Retorno ediciones.

(2013). «Entre costumbrismo y novela: Antonio Liñán y Verdugo y Baltasar Mateo Velázquez». Melánges de la Casa Velázquez, 43, 2, pp. 53-67.

FERNÁNDEZ, Ángel-Raimundo (1983). «Novela corta marginada del siglo XVII. Notas sobre la Guía y avisos de forasteros y El filósofo del aldea». En VV.AA., Homenaje a José Manuel Blecua. Madrid: Gredos, pp. 175-192.

GonzÁlez Ramírez, David (2007). «Lope de Vega y Castillo Solórzano: "Los mejores ingenios de España”. Consideraciones críticas sobre la transmisión, la compilación y la repercusión de las Novelas amorosas (Zaragoza, 1648)». Alazet. Revista de Filologia, 17, pp. 27-54.

(2010). «José Alfay, librero, editor y compilador de Zaragoza. Catálogo comentado de las obras publicadas a su costa». Archivo de Filología Aragonesa, 51, pp. 97-154. (2010). «Rémoras y vagabundos en el Madrid de los Austrias. El mensaje contra la ociosidad de la Guía y avisos de forasteros (1620) entre los arbitrios de la época». Dicenda, 28, pp. 57-72.

(2011). Del taller de imprenta al texto crítico. Recepción y edición de la "Guía y avisos de forasteros» de Liñán y Verdugo. Málaga: Anejos de Analecta Malacitana (Universidad de Málaga).

(2012). «Sobre la prínceps de dos textos póstumos de Castillo Solórzano: Sala de recreación y La quinta de Laura». En Rafael Bonilla, José Ramón Trujillo y Begoña Rodríguez (coords.), Novela corta y teatro en el Barroco español (16131685). Studia in honorem prof. Anthony Close. Madrid, Sial, pp. 55-76.

Moreno, Miguel y Velázquez, Alférez Baltasar Mateo (1906). Novelas. Emilio Cotarelo y Mori (ed.). Madrid: Librería de la Viuda de Rico.

REMón, fray Alonso (1623). Entretenimientos y juegos honestos y recreaciones cristianas, para que en todo género de estados se recreen los sentidos sin que se estrague el alma. Madrid: Viuda de Alonso Martín, a costa de Lucas Ramírez.

(1625). Casa de la razón y el desengaño fundada por hospital moral y doctrinal donde se curen todos los que tiene ciegos, y engañados, y locos el mundo. Madrid: Diego Flamenco, a costa de Juan del Casar.

SARrailh, Jean (1919). «Algunos datos acerca de D. Antonio Liñán y Verdugo, autor de la “Guía y avisos de forasteros” (1620)». Revista de Filología Española, 6, pp. 346-363. 
SARrailh, Jean (1921). «Algunos datos acerca de D. Antonio Liñán y Verdugo, autor de la Guía y avisos de forasteros (1620). II». Revista de Filología Española, 7, pp. 150-160.

VAn PraAg, Jonas A. (1935). «La Guía y avisos de forasteros de Antonio Liñán y Verdugo y El filósofo de la aldea de Baltasar Mateo Velázquez». Bulletin Hispanique, 37, pp. 10-26.

Velasco de la Peña, Esperanza (1998). Impresores y libreros en Zaragoza 1600-1650, Zaragoza: Institución «Fernando el Católico».

Velázquez, Baltasar Mateo (1625). El filósofo del aldea y sus conversaciones familiares y ejemplares por casos y sucesos casuales. Madrid: Diego Flamenco.

Zarco Cuevas, Julián (1929). «¿Quién fue el verdadero autor de la Guía y avisos de forasteros impresa en Madrid en el año 1620?». Boletín de la Real Academia Española, 16, pp. 185-198. 


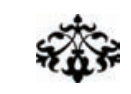

El Filósofo del aldea (1625) de Baltasar Mateo Velázquez: RECEPCIÓN TEXTUAL E HIPÓTESIS AUTORIAL

RESUMEN: El filósofo del aldea (1625) es un libro que presenta una serie de problemas bio-bibliográficos. Fue reeditado a mediados del siglo XVII en Zaragoza (con un añadido apócrifo del propio editor); de esta impresión se han descubierto varios estados de edición diferentes, variando tan solo los preliminares. De su autor no se ha podido rastrear noticia alguna, y la serie de concordancias que presenta con otra obra aparecida solo unos años antes, la Guía y avisos de forasteros (1620) de Liñán y Verdugo, de cuya paternidad solo se tienen sospechas, ha hecho pensar que ambos nombres sean en realidad seudónimos del verdadero autor: Alonso Remón. Laureado dramaturgo, Remón escribió una obra cuya razón de ser guarda similitudes con El filósofo y con la Guía: Entretenimientos y juegos honestos (1623). Un análisis en profundidad de estos tres textos revela un proyecto ideológico de similar naturaleza y carácter.

Palabras clave: Baltasar Mateo Velázquez, Antonio Liñán y Verdugo, Alonso Remón, Filósofo del aldea, Guía y avisos de forasteros, Entretenimientos y juegos honestos, Casa de la razón y del desengaño, Ociosidad, Juegos, Corte, Siglo de Oro.

\section{El filósofo del aldea (1625) BY BALTASAR MATEO VELȦZQUEZ: TEXTUAL RECEPTION AND HYPOTHESES ABOUT ITS AUTHORSHIP}

ABSTRACT: El filósofo del aldea (1625) is a text that presents a series of bio-bibliographical problems. It was reissued around 1650 in Zaragoza (with an apocryphal add of its editor). This print has different editions, varying only its preliminaries texts. However, there is no notice about Baltasar Mateo Velázquez, its alleged author. But there are a series of coincidences with another text, Guía de avisos de forasteros (1620), by Liñán y Verdugo. Furthermore, there are suspicions about the authorship of the latter, leading to think that both names are pseudonyms of a true author: Alonso Remón. This known author wrote a work that shares many similarities with El filósofo and Guía: Entretenimientos y juegos honestos (1623). A deep analysis of these three texts reveals an ideological project, similar in nature and character.

Keywords: Baltasar Mateo Velázquez, Antonio Liñán y Verdugo, Alonso Remón, Filósofo del aldea, Guía y avisos de forasteros, Entretenimientos y juegos honestos, Casa de la razón y del desengaño, Idleness, Plays, Court, Golden Age. 


\section{EDAD DE ORO}

Revista de Filología Hispánica XXXIII

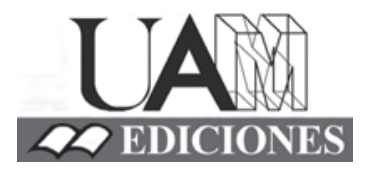




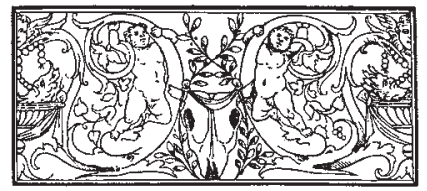

\section{Edad de Oro. Revista de Filología Hispánica}

ISSN: 0212-0429

Dirección:

Teodosio Fernández

Secretaría y edición:

José Ramón Trujillo

Coordinador del volumen XXXIII:

Rafael Bonilla Cerezo

Comité científico internacional:

Carlos Alvar (Univ. de Ginebra)

Ignacio Arellano (Univ. de Navarra)

Javier Blasco (Univ. de Valladolid)

Alberto Blecua (UAB)

Jean Canavaggio (Univ. de París X)

Laura Dolfi (Univ. de Turín)

Aurora Egido (Univ. de Zaragoza)

Víctor García de la Concha (RAE)

Luciano García Lorenzo (CSIC)

Joaquín González Cuenca (Univ. de Castilla-

La Mancha)

Agustín de La Granja (Univ. de Granada)

Begoña López Bueno (Univ. de Sevilla)

Michel Moner (Univ. de Toulouse III)

Joan Oleza (Univ. de Valencia)

Alfonso Rey (Univ. de Santiago)

Lina Rodríguez Cacho (Univ. de Salamanca)

Leonardo Romero Tobar (Univ. de Zaragoza)

Aldo Ruffinatto (Univ. de Turín)

Lía Schwartz (City University of New York)
Redacción y admisión de originales:

Teodosio Fernández

Edad de Oro

Departamento de Filología Española

Universidad Autónoma de Madrid

28049 Madrid (España)

Tfno.: +0034 914974090

correo: teodosio.fernandez@uam.es

Distribución, suscripción y venta:

Servicio de Publicaciones de la UAM

Universidad Autónoma de Madrid

28049 Madrid (España)

Intercambio de publicaciones:

Biblioteca de la Facultad de Filosofía y

Letras (UAM)

Universidad Autónoma de Madrid

28049 Madrid (España)

Han colaborado en este volumen:

Departamento de Filología Española (UAM)

Facultad de Filosofía y Letras (UAM)

Proyecto I+D FFI2013-41264-P La novela

corta del siglo XVII: estudio y edición (y II)

Edad de Oro se recoge en las siguientes bases de datos: SCOPUS, MLA Database, HLAS, Latindex, PIO-Periodical Content Index, ISOC, Dialnet, MIAR, ERIH, DICE, Sumaris CBUC, Ulrich's. Se encuentra evaluada en CIRC: A; INRECH: primer cuartil, posición 6 de 50; MIAR difusión ICDS live: 9.977; SCImago Journal \& Country Rank: H Index 2, SJR 0,101, Q4; RESH índice de impacto: 0.162; ERIH: A INT1; Carhus Plus+: B. 
Evangelina Rodríguez Cuadros (Universitat de València)

Novela cortesana, novela barroca, novela corta: de la incertidumbre al canon 9

Mita Valvassori (Universidad de Los Lagos)

El modelo narrativo del Decamerón en la Edad de Oro: una vieja historia .21

Antonio Gargano (Università degli Studi di Napoli Federico II)

«Difficile est proprie communia dicere»: el género de la novella entre

Boccaccio y Cervantes

Guillermo Carrascón (Università degli Studi di Torino)

Apuntes para un estudio de la presencia de Bandello en la

novela corta del siglo XVII

Leonardo Coppola (Università degli Studi «G. d'Annunzio» di Chieti-Pescara)

La proyección de Straparola en la novela española del Siglo de Oro desde una perspectiva editorial

Mireia Aldomà García

Didactismo, género literario y lector en Giraldi Cinzio

María Jesús Zamora (Universidad Autónoma de Madrid)

«...En tiempo menos discreto que el de agora, aunque de hombres más sabios, se

llamaban a las novelas cuentos». La novela corta y el cuento en el Siglo de Oro......109

Marcial Rubio (Università degli Studi «G. d'Annunzio» di Chieti-Pescara)

La contribución de Cervantes a la novela barroca: la ejemplaridad.

Pierre Darnis (Université Bordeaux Montaigne)

La fuerza de la sangre, La ilustre fregona $y$ Las dos doncellas: ¿tres tipos

folclóricos?

María Soledad Arredondo (Universidad Complutense de Madrid)

De La gitanilla a La sabia Flora malsabidilla. El género, el personaje

y el matrimonio

Antonella Gallo (Università degli Studi di Verona)

Fabulaciones en equívocos burlescos: la Chrónica del monstro imaginado (1615)

de Alonso de Ledesma y novela corta barroca

David González Ramírez (Universidad de Málaga)

El filósofo del aldea (1625) de Baltasar Mateo Velázquez: recepción textual

e hipótesis autorial.

JONATHAN BRADBURY (University of Exeter)

La narrativa breve en la miscelánea del siglo XVII... 
Cristina Castillo Martínez (Universidad de Jaén)

«La fuente del desengaño»: de las Noches de invierno de Eslava a la Tercera

Diana de Tejeda.

MARÍA Zerari (Université Paris-Sorbonne, CLEA)

Furor in fabula: La cruel aragonesa de Castillo Solórzano (o de la dama monstruo).. 241

Giulia Giorgi (Università degli Studi di Ferrara)

Alonso de Castillo Solórzano reescritor de sí mismo: algunas notas sobre los

Escarmientos de amor moralizados y el Lisardo enamorado .257

Angela Fabris (Alpen-Adria-Universität Klagenfurt)

El diálogo con el público y los espacios reales y de maravilla en

Casos prodigiosos y cueva encantada de Juan de Piña 267

María Rocío LePe García (IES San Sebastián, Huelva)

La traducción inglesa de Hipólito y Aminta: una adaptación

con fines comerciales 281

Andrea Bresadola (Università degli Studi di Udine)

La novela española en la Italia del siglo XVII: el caso de Il Feniso

de Francisco de Quintana.

José Teruel (Universidad Autónoma de Madrid)

El triunfo del Desengaño. Marco y desengaño postrero de la Parte segunda

del Sarao y entretenimiento honesto, de María de Zayas

Nieves Romero-Díaz (Mount Holyoke College)

Lecturas alternativas en la Novela del fin bueno en mal principio

de doña Ana Francisca Abarca de Bolea....

Shifra Armon (University of Florida)

Compromiso y distanciamiento en La Venus de Ferrara

de Mariana de Carvajal Saavedra

Mechthild Albert (Rheinische Friedrich-Wilhelms-Universität Bonn)

Las "noches": un subgénero novelístico en perspectiva comparada.... .365

Fernando Copello Jouanchin (Université du Maine, Le Mans)

El mueble en la novela corta del Siglo de Oro: algunas reflexiones

en torno a la cama

Ilaria Resta (Università del Salento):

De la novella al entremés pasando por la novela corta: reescrituras del cuento

La gara delle tre mogli del Cieco di Ferrara. 